\title{
Synthesis of Some Chitosan Derivatives and Their Iron (II) Adsorption Behavior- a Class of Pharmaceutically Important Biosorbents
}

\author{
Tanvir Muslim', Muhammad Tanzirul Alam², Hosne Ara Begum ${ }^{1}$ and Syed Samsul Alam ${ }^{2}$ \\ ${ }^{1}$ Department of Chemistry, University of Dhaka, Dhaka-1000, Bangladesh \\ ${ }^{2}$ Department of Chemistry, Shahjalal University Science and Technology, Sylhet-3114, Bangladesh
}

Received: May 12, 2014; $\quad$ Accepted: June 15, 2014; $\quad$ Published (Web): July 23, 2014

\begin{abstract}
In the present study, chitin was isolated from the shells of freshwater crab (Sartoriana spinigera), available in Bangladesh. The isolated chitin was converted into chtiosan by deacetylation reaction. The chtiosan was characterized by FT-IR and ${ }^{1}$ H-NMR spectral analyses. The prepared chitosan was reacted with glutaradehyde, vanillin and salicylaldehyde to synthesize chitosan Schiff bases- vanillin-chitosan, salicylaldehyde-chitosan and glutaradehyde-chitosan. Iron (II) adsorption behavior of these derivatives was studied under varying experimental conditions such as contact time and initial concentration of iron (II) solution. The equilibrium adsorption data were fitted to Freundlich and Langmuir adsorption isotherm models and the model parameters were evaluated. Both the models represented the experimental data satisfactorily. Maximum adsorption capacity for iron (II) ions on chitosan, vanillin-chitosan, salicylaldehyde-chitosan and glutaradehyde-chitosan was evaluated and found be to $68.03,35.59,7.50$ and $4.78 \mathrm{mg} / \mathrm{g}$, respectively. The uses of chitosan derivatives as environment friendly biosorbents in pharmaceutical and API industries have been hightlighted.
\end{abstract}

Key words: Crab shells, Chitosan, Schiff bases, Iron (II), Adsorption.

\section{Introduction}

Chitosan is a polymer of $\beta(1 \rightarrow 4)$-D-glucosamine and has no or small amount of $N$-acetyl-D-glucosamine units. It is obtained by alkaline $N$-deacetylation of chitin (Figure $1)$. Chitin is a polysaccharide made up of $\beta(1 \rightarrow 4)$-linked $\mathrm{N}$-acetyl-D-glucosamine that is widely found in nature forming exoskeletons of crustaceans such as crabs, lobsters, krill and shrimps, and insects as well as components of bacterial cell walls (Rinaudo, 2006). Due to their biodegradability, biocompatibility and bioactivities, chitin and chitosan have created significant interests in biomedical applications (Shigemasa, 1995). Chitosan has been used as biomaterials in veterinary practice to activate host defenses in preventing infection and to accelerate the wound healing. Due to the chelating property, chitosan is widely used for the treatment of environmental pollution and wastewater (Muzzarelli, 1973; No, 2000). Introducing various substituents and also crosslinks, chemically modified chitosan derivatives are expected to improve the bioactivities and the chelating properties (Muslim et al., 2001a; Bhatnagar, 2009; Sashiwa, 2004). Applications of chitosan derivatives in the field biomedicine, nutrition, food processing, pharmacology, microbiology, agriculture and cosmetics are increasing day by day (Goosen, 1996). Numarous reports have been published related to the bioactivities of different chitosan derivatives (Nishimura et al., 1986; Murata et al., 1989; Dutkiewicz et al., 1990; Tanigawa et al., 1992; Yalpani et al., 1992; Terada et al., 1999; Muslim et al., 2001b). Various applications of chitosan and chitosan derivatives in pharmaceutical industries have also been reported (Kumar et al., 2004; Sarmento, 2012; Kim, 2013).

The amino group at 2-position of monosaccharide unit of chitosan can be chemically modified to get new derivatives, including Schiff base by reaction with aldehydes and ketones and acylation using acid anhydride or acid chloride. Hirano et al. (1979) reported the preparation and properties of some $N$-arylidenechitosan gels. Hall and Yalpani (1980) prepared chitosan derivative of salicylaldehyde to enhance the metal-chelating properties of chitin and chitosan. Muzzarelli and Ilari (1994) prepared film using chitosan derivatives of $o$-vanillin, vanillin, syringaldehyde and veratraldehyde.

Correspondence to: Tanvir Muslim; E-mail : tmuslim@gmail.com 
Antifungal activity of Schiff bases of chitosan has been reported (Guo et al., 2007). Glutaraldehyde cross-linked chitosan microspheres was utilized as a long acting biodegradable drug delivery vehicle (Jameela, 1995; Gupta, 2007).

In Bangladesh, crab shells are used as one of the most important raw materials to produce animal feed. On the contrary, the United States and Japan have utilized crab shells as raw material to produce the chitin and chitosan and their derivatives. Sartoriana spinigera (Wood-Mason, 1871) is the commonest freshwater crab of Bangladesh and found near tanks, jheels and rivers. Utilization of the crab shells as raw materials for the preparation of chitosan and chitosan derivatives is promising in Bangladesh.

In the present investigation, chitosan and chitosan derivatives have been prepared from shells of locally available freshwater crab (Sartoriana spinigera). The aim of this work was to utilize the potential of the prepared chitosan derivatives as biosorbents for pharmaceutical process industries. Iron (II) adsorption behavior of these derivatives has been studied under varying experimental conditions such as contact time and initial concentration of iron solution.

\section{Materials and Methods}

All chemicals and solvents used in the present work were analytical grade (Merck and $\mathrm{BDH})$. All solvents were distilled before use. Different solutions and reagents were prepared using standard analytical procedures.

Collection and preparation of samples: The raw shells of freshwater crab (Sartoriana spinigera) were collected from Tangail, Bangladesh. The raw crab shells were washed with water and dried in the sun for 3 days. After drying, the dried materials were ground into small pieces and kept in air tight container.

Isolation of chitin from crab shells: Chitin was isolated from the dried crab shells as described previously with minor modification (Rødde et al., 2008). The process mainly involved the following steps:

(i) Demineralization of crab shells: The dried crab shells was dematerialized with hydrochloric acid solution $(1.0 \mathrm{M})$ at room temperature with constant stirring for 24 hours, using a ratio of solid to acidic solution of 1:13 $(\mathrm{w} / \mathrm{v})$. When the crab shells became quite squashy, they were rinsed with distilled water to remove acid and salt.
The decalcified product was washed with methanol and acetone. The washed material was transferred to a glass tray, and dried for overnight at $60^{\circ} \mathrm{C}$ in an oven.

(ii) Deproteinization of crab shells: Deproteinization was carried out by slowly adding the dematerialized crab shells to sodium hydroxide solution $(1.0 \mathrm{M})$ to obtain a ratio of solid to alkaline solution of 1:13 (w/v). The temperature of the reaction mixture was maintained at $90^{\circ} \mathrm{C}$ with constant stirring for 2.5 hours. The residue was then collected and washed with distilled water until the $\mathrm{pH}$ became neutral. Then it was washed with organic solvents and dried, as described above. The final product was obtained as chitin
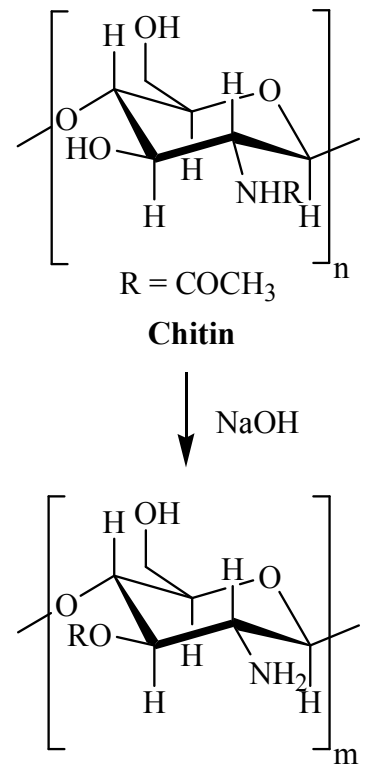

Chitosan

Figure 1. Preparation of chitosan from chitin by deacetylation.

Preparation of chitosan from isolated chitin: Chitosan was prepared from isolated chitin of crab shells as described previously with minor modification (Rødde et al., 2008). The reaction is shown in Figure 1. Isolated chitin was slowly added into a flask containing a solution of sodium hydroxide $(40 \%, \mathrm{w} / \mathrm{v})$ to obtain a ratio of solid to alkaline solution of $1: 15(\mathrm{w} / \mathrm{v})$. The temperature of the reaction mixture was maintained at $100^{\circ} \mathrm{C}$ and refluxed under nitrogen atmosphere for 8 hours to remove some or all of the acetyl groups from amino groups on the polymer. The prepared chitosan was dissolved in acetic acid solution $(5 \%, \mathrm{w} / \mathrm{v})$ to obtain a ratio of solid to acidic solution of $1: 10(\mathrm{w} / \mathrm{v})$ and it was stirred continuously for 
two hours. The solution was kept over night and centrifuged. The clear supernatant liquid was taken in a beaker and sodium hydroxide solution $(5 \%, \mathrm{w} / \mathrm{v})$ was added drop wise into the acidic chitosan solution to obtain the precipitate of purified chitosan. The precipitate was thoroughly washed with distilled water until the $\mathrm{pH}$ became neutral. Finally, the purified chitosan was washed with organic solvents and dried in a similar way it was done for the chitin sample.

Characterization of chitosan: FT-IR spectrum of prepared chitosan was recorded using a FTIR spectrophotometer (FT-IR 8400S, Shimadzu, Japan) within the range of $400-4000 \mathrm{~cm}^{-1}$ as $\mathrm{KBr}$ disc.

${ }^{1} \mathrm{H}-\mathrm{NMR}$ spectrum of chitosan was recorded on a JEOL JNM-GX270 spectrometer. Chitosan was dissolved in $\mathrm{D}_{2} \mathrm{O}$ containing a few drops of $20 \mathrm{wt} \% \mathrm{DCl} / \mathrm{D}_{2} \mathrm{O}$ (Shigemasa et al., 1996). The chemical shifts were referenced from DSS (sodium 2,2-dimethyl-2-silapentane5 -sulfonate).

Degree of deacetylation (DDA) of the prepared chitosan was determined by ${ }^{1} \mathrm{H}-\mathrm{NMR}$ spectroscopy using method described by Vårum et al. (1991).

Preparation of vanillin-chitosan: Vanillin-chitosan was prepared according to the method described by Hirano et al. (1979) with slight modifications. The reaction is shown in Figure 2. Chitosan $(4.0 \mathrm{~g})$ was dissolved by stirring in acetic acid $(2 \%, 80 \mathrm{ml})$ at room temperature to give a viscous solution. Methanol $(80 \mathrm{ml})$ was added to dilute the solution. Vanillin $(3.8 \mathrm{~g})$ was dissolved in methanol $(80 \mathrm{ml})$ and vanillin solution was poured into the chitosan solution with stirring. A bright yellow highly viscous solution was formed and it was kept on stirring for $6 \mathrm{~h}$ and kept for overnight at room temperature to form Schiff base. The whole solution was solidified to afford vanillin-chitosan gel. Aqueous $\mathrm{NaOH}$ solution $(40 \%, 10 \mathrm{ml})$ was added drop wise to the Schiff base to reduce the solubility of the gel. The gel was broken up in to small pieces and methanol was added. The color of the gel turned yellow. The gel was washed for several times with water and then methanol to remove the unreacted reagents. The final dried product was light yellow solid $(3.9 \mathrm{~g})$. The vanillin-chitosan was characterized by FT-IR.
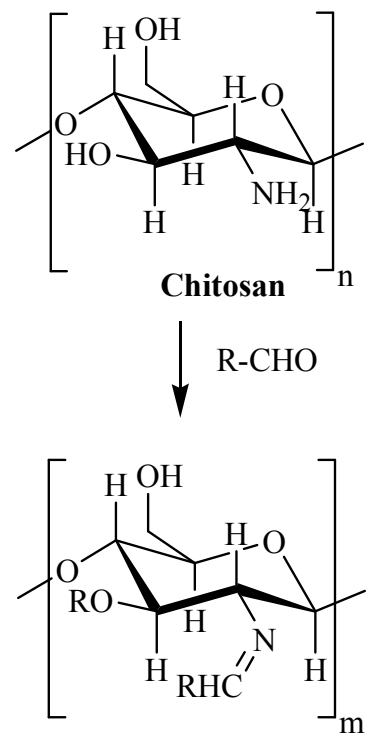

Vanillin-chitosan : $\mathrm{R}=\mathrm{OCH}_{3}$

Salicylaldehyde-chitosan :

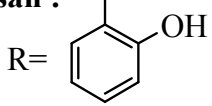

Figure 2. Preparation of vanillin-chitosan and salicyladehydechitosan from chitosan.

Preparation of salicylaldehyde-chitosan: Salicylaldehyde-chitosan was prepared according to the method described above (Figure 2). For this, chitosan (4 g) was dissolved in acetic acid $(2 \%, 80 \mathrm{ml})$ by stirring at room temperature to give a viscous solution. Methanol $(80 \mathrm{ml})$ was added to dilute the solution. Salicylaldehyde $(5.2 \mathrm{ml})$ was dissolved in methanol $(80 \mathrm{ml})$ and this solution was poured into the chitosan solution with stirring. A yellowish high viscous solution was formed and it was kept on stirring for $6 \mathrm{~h}$ and stayed for overnight at room temperature to form Schiff base. The whole solution was solidified to afford salicylaldehyde-chitosan gel. Aqueous sodium hydroxide solution $(40 \%, 10 \mathrm{ml})$ was added drop wise to the Schiff base to reduce the solubility of the gel. The gel was broken up into small pieces and methanol was added. The color of the gel was yellow. The gel was washed for several times with water and then methanol to remove the excess reagents. The final product was light yellow solid (3.9 g). The salicylaldehyde-chitosan was characterized by FT-IR. 

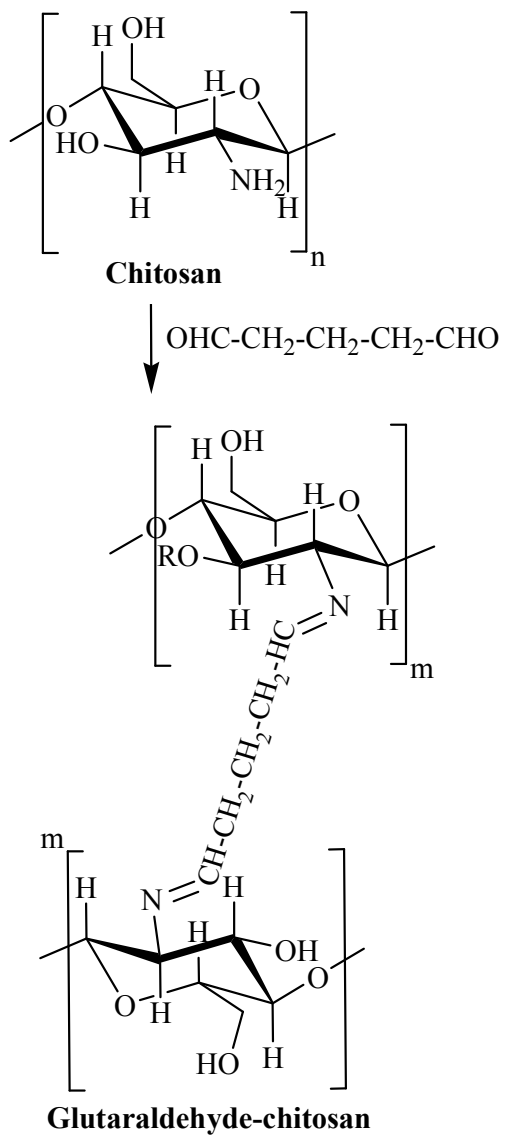

Figure 3: Preparation of glutaraldehyde-chitosan from chitosan.

Preparation of glutaraldehyde-chitosan: Glutaraldehyde-chitosan was prepared according to the previously described method with slight modifications (Guibal et al., 1979). The reaction is shown in Figure 3. Chitosan (2 g) was added to aqueous glutaraldehyde solution $(25 \mathrm{~g}, 25 \%$ $\mathrm{w} / \mathrm{w})$ with stirring at room temperature. It was kept on stirring for $12 \mathrm{~h}$ to give a crossed linked glutaraldehydechitosan gel. The gel was broken up in to small pieces and methanol was added to it. The color of the gel was yellow. The gel was washed for several times with water and then methanol to remove the excess reagents. The final dried product was light yellowish solid $(2.2 \mathrm{~g})$. The glutaraldehyde-chitosan was characterized by FT-IR.

Adsorption study: Stock solution $(1000 \mathrm{mg} / \mathrm{l})$ of iron (II) ion was prepared by using $\mathrm{FeSO}_{4} \cdot 7 \mathrm{H}_{2} \mathrm{O}$ in deionized double distilled water (DDW). The stock solution was then diluted to give standard solutions of appropriate concentrations. The concentration of iron (II) in the solution was determined spectrophotometrically as the color complex which was formed when iron (II) reacted with 1,10-phenanthroline (Christian, 1986). The absorbance of the colored complex of iron (II) with 1,10phenanthroline was recorded at $\lambda_{\max } 510 \mathrm{~nm}$ using a UVVisible spectrophotometer (Shimadzu UV-1650, Japan) at $30^{\circ} \mathrm{C}$. A calibration curve was prepared by recording the absorbance values for iron (II) solutions of known concentrations. Unknown concentration of iron (II) in the solution was estimated using this calibration curve.

Estimation of the equilibrium time: The equilibrium times of the adsorption of iron (II) on chitosan, vanillinchitosan, salicylaldehyde-chitosan and glutaradehydechitosan were estimated at $\mathrm{pH} 3.5$. For this, $0.02 \mathrm{~g}$ of each sample (particle size: $212-300 \mu \mathrm{m}$ ) and $25 \mathrm{ml}$ of $70 \mathrm{mg} / \mathrm{l}$ iron (II) solution was used in each of the bottles. The bottles were shaken in a thermostatic mechanical shaker at $30^{\circ} \mathrm{C}$. For blank $0.02 \mathrm{~g}$ of each sample and $25 \mathrm{ml}$ of DDW solution added in a bottle and was shaken for 6 hours at $30^{\circ} \mathrm{C}$. After a definite interval of time, each of the bottles was withdraw from the shaker. The supernatant of the bottle was transferred and centrifuged repeatedly until a clear liquid was obtained. Iron (II) concentration of the solutions was estimated by spectrophotometric method, mentioned above (Christian, 1986). The amount of iron (II) adsorbed at time $\mathrm{t}(\mathrm{mg} / \mathrm{g}), \mathrm{q}_{\mathrm{t}}$, on chitosan or chitosan derivative was calculated by a mass balance relationship,

$$
\mathrm{q}_{\mathrm{t}}=\left(\mathrm{C}_{0}-\mathrm{C}_{\mathrm{t}}\right) \mathrm{V} / \mathrm{m}
$$

At equilibrium time, the amount of iron (II) adsorbed $\mathrm{q}_{\mathrm{e}}(\mathrm{mg} / \mathrm{g})$, was calculated by the following relationship,

$$
\mathrm{q}_{\mathrm{e}}=\left(\mathrm{C}_{0}-\mathrm{C}_{\mathrm{e}}\right) \mathrm{V} / \mathrm{m}
$$

where, $\mathrm{C}_{0}$ is the initial concentration of iron (II) in the solution ( $\mathrm{mg} / \mathrm{l}), \mathrm{C}_{\mathrm{t}}$ is the residual concentration of iron (II) in the solution at any time $\mathrm{t}(\mathrm{mg} / \mathrm{l}), \mathrm{C}_{\mathrm{e}}$ is the residual dye concentration in the solution at equilibrium time $(\mathrm{mg} / \mathrm{l}), \mathrm{V}$ is the solution volume (L) and $\mathrm{m}$ is the mass of adsorbent (g). The plots of amount of iron (II) adsorbed at time $t, q_{t}$ $(\mathrm{mg} / \mathrm{g})$ versus the time, $\mathrm{t}(\mathrm{h})$ of adsorption for chitosan and its derivatives have been presented in Figure 4.

Adsorption isotherms of iron (II) on chitosan and its derivatives: Adsorption isotherms were carried out on chitosan and its derivatives using different initial iron (II) concentrations $(11,15,19.5,30.7,51.2,72.4,104$ and 146 $\mathrm{mg} / \mathrm{l})$ at $\mathrm{pH} 3.5$ and $30^{\circ} \mathrm{C} .25 \mathrm{ml}$ of each solution was taken in each bottle. The bottles were shaken in thermostatic mechanical shaker at $30^{\circ} \mathrm{C}$ for $20 \mathrm{~h}$. The bottles were withdrawn at the stipulated time from the shaker and supernatant was transferred to the centrifuge 
tube for centrifugation. The concentration of iron (II) was estimated spectrophotometrically (Christian, 1986). The plots of amount of iron (II) adsorbed at equilibrium, $\mathrm{q}_{\mathrm{e}}$ $(\mathrm{mg} / \mathrm{g})$ versus initial concentration of iron (II) in the solution, $\mathrm{C}_{0}(11,15,19.5,30.7,51.2,72.4,104$ and 146 $\mathrm{mg} / \mathrm{l}$ ) for chitosan and its derivatives are shown in Figure 5. The plots of amount of iron (II) adsorbed at equilibrium, $\mathrm{q}_{\mathrm{e}}(\mathrm{mg} / \mathrm{g})$ versus equilibrium concentration of iron (II) in the solution, $\mathrm{C}_{\mathrm{e}}(\mathrm{mg} / \mathrm{l})$ for chitosan and its derivatives are shown in Figure 6.

\section{Results and Discussion}

Preparation of chitosan: In the present study, shells of freshwater crab (Sartoriana spinigera) were used as raw material for the preparation of chitosan. Chitin was extracted from the dried freshwater crab shells following previously described procedure (Rødde et al., 2008). The extraction of chitin from crab shells involved two steps, demineralization to remove calcium carbonate using hydrochloric acid and deproteinization to remove proteins with sodium hydroxide. The yield of extracted chitin with these conditions was $11.82 \%$ of the total weight of the dried crab shells. The chitin obtained was then deacetylated with conc. sodium hydroxide solution. The yield of resulting chitosan was found to be $8.84 \%$ of the total weight of the dried crab shells. The characterization of the prepared chitosan was done by FT-IR and ${ }^{1} \mathrm{H}-\mathrm{NMR}$ spectroscopy.

Characterization of chitosan: To characterize chitosan prepared from crab shells, the FT-IR spectrum was recorded and absorption bands were compared to those of standard chitosan (Kumirska et al., 2010). The FT-IR spectrum showed a broad absorption band at around 3367 $\mathrm{cm}^{-1}$ corresponding to the stretching vibration of hydrogen bonded $\mathrm{O}-\mathrm{H}$ and $\mathrm{N}-\mathrm{H}$ bonds. The spectra also shared characteristic peaks of amide $\mathrm{I}$ at $1651 \mathrm{~cm}^{-1}(\mathrm{C}=\mathrm{O}$ stretching), amide II at $1596 \mathrm{~cm}^{-1}(\mathrm{~N}-\mathrm{H}$ in plane deformation coupled with $\mathrm{C}-\mathrm{N}$ stretching) amide III (C-N stretching coupled with $\mathrm{O}-\mathrm{H}$ in plane deformation) and $\mathrm{CH}_{2}$ wagging coupled with $\mathrm{O}-\mathrm{H}$ in plane deformation at $1319 \mathrm{~cm}^{-1}$. The bands observed at around 2922 and 2879 $\mathrm{cm}^{-1}$ were assigned to $\mathrm{sp}^{3} \mathrm{C}-\mathrm{H}$ stretching (symmetric and asymmetric). The band at $1379 \mathrm{~cm}^{-1}$ corresponded to $\mathrm{C}-\mathrm{H}$ bending and symmetric $-\mathrm{CH}_{3}$ deformation. The band observed at $1417 \mathrm{~cm}^{-1}$ was due to $>\mathrm{CH}_{2}$ bending and $-\mathrm{CH}_{3}$ deformation. The band observed at $1153 \mathrm{~cm}^{-1}$ was indicated at bridged oxygen stretching $(\mathrm{C}-\mathrm{O}-\mathrm{C}$ linkage of ring). The $\mathrm{C}-\mathrm{O}$ stretching vibration bands were observed at 1076 and $1029 \mathrm{~cm}^{-1}$. The characteristic signal for $\mathrm{CH}$ deformation of the $\beta$-glycosidic bond was observed at 898 $\mathrm{cm}^{-1}$.

The ${ }^{1}$ H-NMR spectrum of chitosan prepared from crab shells was recorded and signals were compared to those of standard chitosan (Kumirska et al., 2010). The spectrum showed two signals in the anomeric region, namely $\mathrm{H}-1$ of glucosamine $(\mathrm{GlcN})$ residue at $\delta 4.85$ and $\mathrm{H}-1$ of $N$-acetyl glucosamine (GlcNAc) residue at $\delta 4.5$. They were shifted to higher values due to the neighboring glycosidic and oxygen atoms of the ring. The resonances of H-3-H-6 ring protons of GlcN and H-2-H-6 of GlcNAc appeared in the middle of the spectrum $(\delta 3.6-3.85)$, forming a group of broad, overlapping signals. The remaining $\mathrm{H}-2$ ring protons of GlcN residues were shifted to characteristically lower values $(\delta 3.15)$ because of the adjacent amino group. The characteristic signal of the protons in the $\mathrm{N}$ acetyl group (GlcNAc) was at $\delta 2.03$. The FT-IR and ${ }^{1} \mathrm{H}-$ NMR spectral analysis indicated the successful conversion of isolated chitin into chitosan.

Determination of degree of deacetylation (DDA) of chitosan is essential to study structure-property relationships. Degree of deacetylation (DDA) of prepared chitosan was determined by ${ }^{1} \mathrm{H}-\mathrm{NMR}$ spectroscopy and found to be $81.36 \%$ (Vårum et al., 1991).

Characterization of chitosan derivatives: The synthesized vanillin-chitosan derivative was characterized by FT-IR spectroscopy. The absorption bands in the FT-IR spectrum of vanillin-chitosan derivative were compared to those of reported data (Peng et al., 2010). The following different characteristic signals were assigned from the FTIR spectrum. The spectrum showed a broad absorption band at around $3385 \mathrm{~cm}^{-1}$ corresponding to the stretching vibration of hydrogen bonded $\mathrm{O}-\mathrm{H}$ and $\mathrm{N}-\mathrm{H}$ bonds. The band showed at $1654 \mathrm{~cm}^{-1}$ corresponding to characteristic stretching vibration of $\mathrm{C}=\mathrm{N}$, which can be attributed to the Schiff base reaction between the aldehyde group of vanillin and amino group of chitosan. The absorption band at $1500 \mathrm{~cm}^{-1}$ was attributed to the $\mathrm{C}=\mathrm{C}$ stretching in the aromatic ring of vanillin. The $\mathrm{C}-\mathrm{O}$ stretching vibration bands were observed at 1280 and $1074 \mathrm{~cm}^{-1}$. The absorption band at $858-700 \mathrm{~cm}^{-1}$ was attributed to 
aromatic out of plane $\mathrm{C}-\mathrm{H}$ bending. From these results it was confirmed that chitosan was linked by vanillin successfully through Schiff base reaction.

The synthesized salicylaldehyde-chitosan derivative was characterized by FT-IR spectroscopy. The absorption bands of FT-IR spectrum of salicylaldehyde-chitosan derivative were compared to those of with reported data (dos Santos et al., 2005). The FT-IR spectrum displayed a broad absorption band at around $3385 \mathrm{~cm}^{-1}$ corresponded to the stretching vibration of hydrogen bonded $\mathrm{O}-\mathrm{H}$ and $\mathrm{N}-\mathrm{H}$ bonds. The band showed at $1655 \mathrm{~cm}^{-1}$ corresponding to characteristic stretching vibration of $\mathrm{C}=\mathrm{N}$, which can be attributed to the Schiff base reaction between the aldehyde group of salicylaldehyde and amino group of chitosan. The absorption band at $1481 \mathrm{~cm}^{-1}$ was attributed to the $\mathrm{C}=\mathrm{C}$ stretching in the aromatic ring of salicylaldehyde. The $\mathrm{C}-\mathrm{O}$ stretching vibration bands were observed at 1236 and $1070 \mathrm{~cm}^{-1}$. The absorption band at $831-716 \mathrm{~cm}^{-1}$ was attributed to aromatic out of plane $\mathrm{C}-\mathrm{H}$ bending.

To characterize synthesized glutaraldehyde-chitosan, the FT-IR spectrum was recorded and compared to those of glutaraldehyde-chitosan (Poon et al., 2014). The characteristic bands were assigned from the spectrum. The broad and strong band at the region $3300-3500 \mathrm{~cm}^{-1}$ is characteristic of the $-\mathrm{NH}$ and $-\mathrm{OH}$ stretching vibration. An absorption band at $1651 \mathrm{~cm}^{-1}$ was observed corresponding to stretching vibrations of $\mathrm{C}=\mathrm{N}$ bond. This band indicated the formation of Schiff base as a result of the reaction between aldehyde group of glutaraldehyde and the amine group of chitosan. The presence of the band at $1020 \mathrm{~cm}^{-1}$ indicated stretching vibration of the $\mathrm{C}-\mathrm{O}$ bond and an asymmetric $\mathrm{C}-\mathrm{O}-\mathrm{C}$ stretching band in the $1145 \mathrm{~cm}^{-1}$ region, defined by the glycosidic linkage in the polymer chain.

\section{Adsorption studies}

Estimation of equilibrium time: In order to determine the adsorption equilibrium time, the adsorption of iron (II) onto chitosan, vanillin-chitosan, salicylaldehyde-chitosan and glutaradehyde-chitosan was studied as a function of contact time. The adsorption experiments were carried out at $\mathrm{pH} 3.5$ and at $30^{\circ} \mathrm{C}$ using iron (II) solution with an initial concentration of $70 \mathrm{mg} / \mathrm{l}$. The amount of adsorbent taken for each experiment was $0.02 \mathrm{~g}$. Figure 4 shows the time profiles of iron (II) adsorption onto chitosan and its derivatives. Rapid adsorption was found during the adsorption time of 4 hours. Then the adsorption process progressed very slowly. The removal of iron (II) on absorbent was found to be approximately constant within 20 hours for all adsorbents.

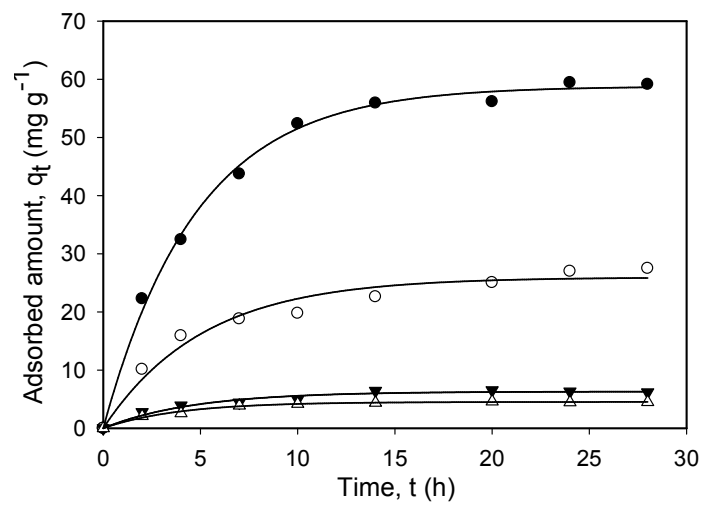

Figure 4. A plot of amount iron (II) adsorbed versus time for the estimation of equilibrium time for chitosan and chitosan derivatives. $(\bullet \rightarrow$ chitosan, $\mathrm{O} \rightarrow$ vanillin-chitosan and $\boldsymbol{\nabla} \rightarrow$ salicylaldehyde-chitosan and $\triangle \rightarrow$ glutaraldehydechitosan)

Effect of initial concentration of iron (II) solution on adsorption: The initial concentration provides an important force to overcome all mass transfer resistances of all molecules between the aqueous and solid phases (Ho et al., 2005; Doğan et al., 2006). The effect of initial iron (II) concentration in the range of 11 to $146 \mathrm{mg} / \mathrm{l}$ on adsorption (investigated under the specified conditions: initial $\mathrm{pH}$ of 3.5 ; contact time of 20 hours; adsorbent dosage of $0.02 \mathrm{~g}$ per $25 \mathrm{ml}$; and temperature of $30^{\circ} \mathrm{C}$ ) is shown in Figure 5. The adsorption increases with increase of initial concentration of iron (II) solution. The amount of adsorbate in the solid phase with lower initial concentration of adsorbate was smaller than the amount when higher concentrations were used.

Adsorption isotherms: The adsorption isotherm indicates how the dye molecules distribute between the liquid phase and the solid phase when the adsorption process reaches an equilibrium state. The adsorption isotherms of iron (II) ions on chitosan, vanillin-chitosan, salicylaldehyde-chitosan and glutaradehyde-chitosan were studied at $30^{\circ} \mathrm{C}$. The amount of iron (II) adsorbed, $\mathrm{q}_{\mathrm{e}}$, on chitosan and its derivatives increased with the increment of equilibrium concentration, $\mathrm{C}_{\mathrm{e}}$ (Figure 6 ). The analysis of the isotherm data by fitting them to different isotherm 
models is an important step to find the suitable model that can be used for designing the adsorption purpose. The Langmuir and Freundlich adsorption models were used for the mathematical description of the biosorption of iron (II) (Langmuir, 1916; Freundlich, 1906).

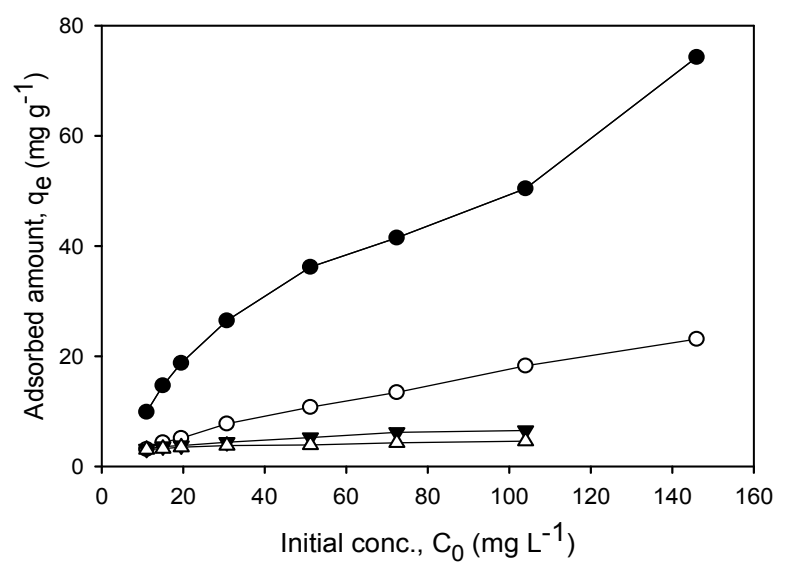

Figure 5. Amount iron (II) adsorbed on chitosan and chitosan derivatives at different initial concentrations. $(\rightarrow$ chitosan, $\mathrm{O} \rightarrow$ vanillin-chitosan, $\quad \boldsymbol{\nabla} \rightarrow$ salicylaldehyde-chitosan, $\Delta \rightarrow$ glutaraldehyde-chitosan).

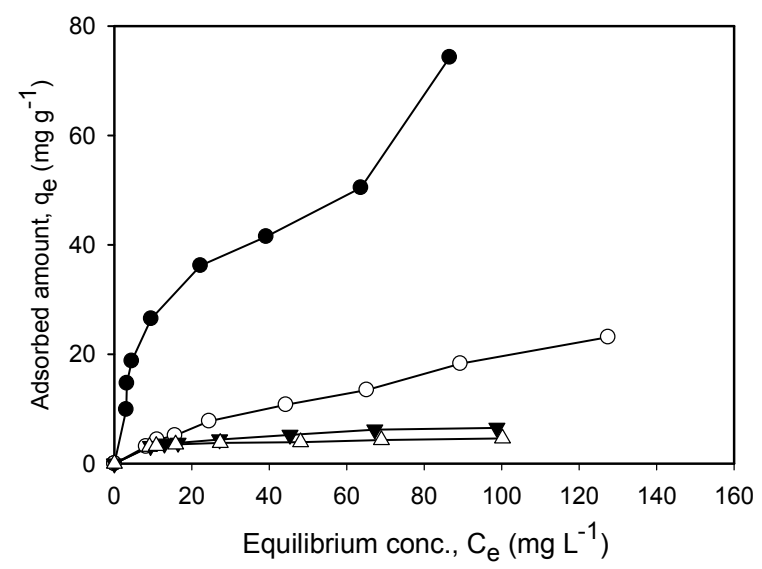

Figure 6. Amount iron (II) adsorbed on chitosan and chitosan derivatives at different equilibrium concentrations. $(\rightarrow$ chitosan, $\mathrm{O} \rightarrow$ vanillin-chitosan, $\boldsymbol{\nabla} \rightarrow$ salicylaldehyde-chitosan, $\triangle \rightarrow$ glutaraldehyde-chitosan).

The simple Langmuir model in based on the assumption that the solid surface has a limited adsorption capacity that is energetically and sterically independent of the adsorbent quantity, valid for monolayer sorption. The linearized expression of the Langmuir isotherm is shown in equation (3):

$$
\frac{\mathrm{C}_{\mathrm{e}}}{\mathrm{q}_{\mathrm{e}}}=\frac{\mathrm{C}_{\mathrm{e}}}{\mathrm{q}_{\mathrm{m}}}+\frac{1}{\mathrm{q}_{\mathrm{m}} \mathrm{K}_{\mathrm{L}}}
$$

where, $\mathrm{C}_{\mathrm{e}}$ is the solute equilibrium concentration in the liquid phase $(\mathrm{mg} / \mathrm{l}), \mathrm{q}_{\mathrm{e}}$ is the amount of solute adsorbed per mass of adsorbent $(\mathrm{mg} / \mathrm{g}), \mathrm{q}_{\mathrm{m}}$ characterizes the saturated adsorption capacity $(\mathrm{mg} / \mathrm{g})$ and $\mathrm{K}_{\mathrm{L}}$ is related to the affinity of the sorbate for the adsorbent $(\mathrm{L} / \mathrm{mg})$. The linearized Langmuir plots of $\mathrm{C}_{\mathrm{e}} / \mathrm{q}_{\mathrm{e}}$ against $\mathrm{C}_{\mathrm{e}}$ are shown in Figure 7. From the slopes and intercepts of equation (3), the values of $\mathrm{q}_{\mathrm{m}}$ and $\mathrm{K}_{\mathrm{L}}$ were calculated.

The Freundlich model for metal sorption is based on the relation between the adsorbed quantity and the solute concentration remained in the liquid phase, expressed in linearized form in equation (4):

$$
\log \mathrm{q}_{\mathrm{e}}=\log \mathrm{K}_{\mathrm{F}}+\frac{1}{\mathrm{n}} \log \mathrm{C}_{\mathrm{e}}
$$

where, $K_{F}$ and $1 / n$ are the Freundlich constants; $K_{F}$ represents the relative sorption capacity, and $1 / \mathrm{n}$ characterizes the nature and the intensity of the sorption process and the distribution of active sites. The linearized Freundlich plots of $\log \mathrm{q}_{\mathrm{e}}$ against $\log \mathrm{C}_{\mathrm{e}}$ are shown in Figure 8. From the slopes and intercepts of equation (4), the values of $n$ and $K_{F}$ were calculated.

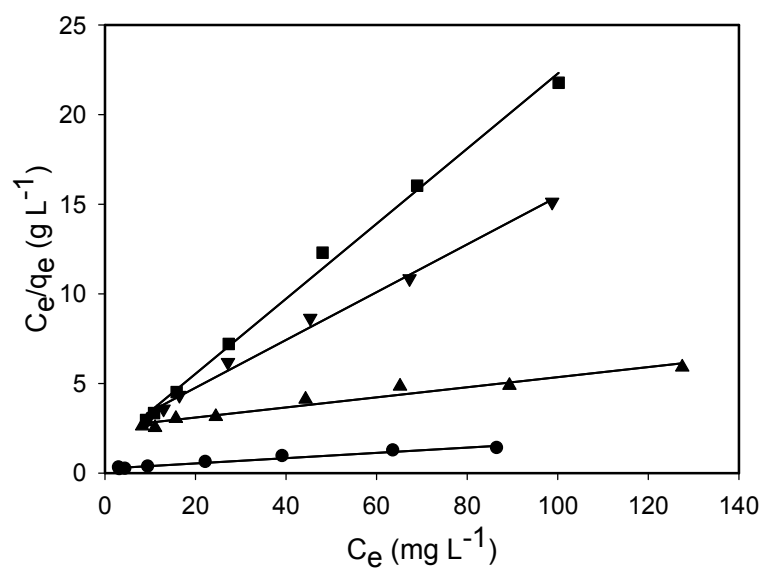

Figure 7. Langmuir adsorption isotherms of $\mathrm{Fe}(\mathrm{II})$ on chitosan and different chitosan derivatives at $30^{\circ} \mathrm{C} .(\bullet \rightarrow$ chitosan, $\boldsymbol{\Delta} \rightarrow$ vanillin-chitosan, $\quad \boldsymbol{\nabla} \rightarrow$ salicylaldehyde-chitosan, glutaraldehyde-chitosan).

The equilibrium adsorption data were fitted to Freundlich and Langmuir adsorption isotherm models and the model parameters were evaluated. Both the models represent the experimental data satisfactorily. The 
Langmuir and Freundlich adsorption parameters are given in Table 1. Values of $\mathrm{n}$ calculated from Freundlich plots indicated that adsorption of iron (II) on chitosan and its derivatives were spontaneous. Maximum adsorption capacity for iron (II) ions on chitosan, vanillin-chitosan, salicylaldehyde-chitosan and glutaradehyde-chitosan was evaluated from Langmuir plots and found be to 68.03, $35.59,7.50$ and $4.78 \mathrm{mg} / \mathrm{g}$, respectively. It indicated that the adsorption capacity of adsorbent decreased in the order chitosan $>$ vanillin-chitosan $>$ salicylaldehyde-chitosan $>$ glutaradehyde-chitosan. The amine groups $\left(-\mathrm{NH}_{2}\right)$ of the chitosan acted as adsorption sites. The lone pair electrons

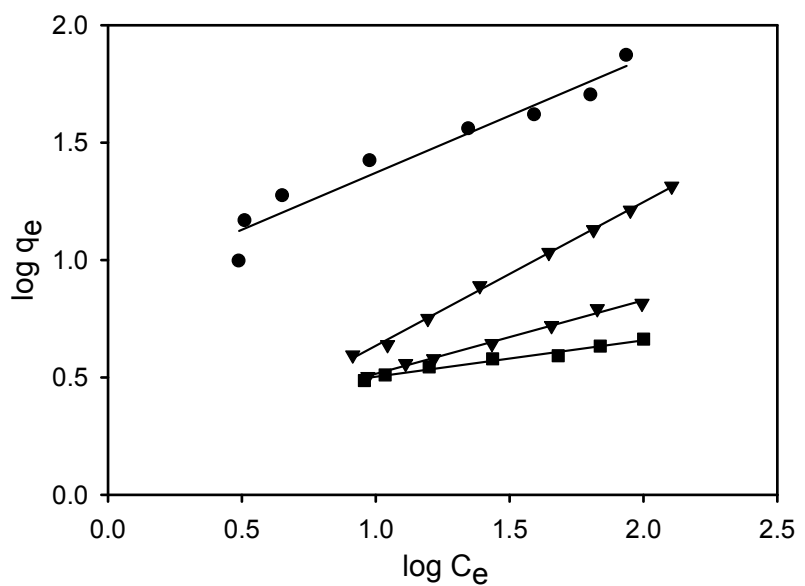

Figure 8. Freundlich adsorption isotherms of iron (II) on chitosan and chitosan derivatives at $30^{\circ} \mathrm{C}$. $(\bullet$ chitosan, $\boldsymbol{\Delta} \rightarrow$ vanillin-chitosan, $\quad \boldsymbol{\nabla} \rightarrow$ salicylaldehyde-chitosan, glutaraldehyde-chitosan)

Table 1. Langmuir and Freundlich parameters of adsorption of iron (II) on chitosan and chitosan derivatives

\begin{tabular}{ccccccc}
\hline & \multicolumn{2}{c}{ Langmuir } & \multicolumn{4}{c}{ Freundlich } \\
\cline { 2 - 7 } Adsorbent & $\mathrm{r}^{2}$ & $\begin{array}{c}\mathrm{q}_{\mathrm{m}} \\
\mathrm{mg} \mathrm{g}^{-1}\end{array}$ & $\begin{array}{c}\mathrm{K}_{\mathrm{L}} \\
\mathrm{L} \mathrm{mg}^{-1}\end{array}$ & $\mathrm{r}^{2}$ & $\begin{array}{c}\mathrm{K}_{\mathrm{F}} \\
\mathrm{mg}^{(1-\mathrm{n})} \mathrm{L}^{\mathrm{n}} \mathrm{g}^{-1}\end{array}$ & $\mathrm{n}$ \\
\hline $\mathrm{C}$ & 0.97 & 68.03 & 0.060 & 0.94 & 7.69 & 2.06 \\
$\mathrm{~V}$ & 0.95 & 35.59 & 0.011 & 0.99 & 1.05 & 1.64 \\
$\mathrm{~S}$ & 0.99 & 7.50 & 0.063 & 0.99 & 1.59 & 3.19 \\
$\mathrm{G}$ & 0.99 & 4.78 & 0.154 & 0.97 & 2.23 & 6.44 \\
\hline
\end{tabular}

$(\mathrm{C} \rightarrow$ chitosan, $\mathrm{V} \rightarrow$ vanillin-chitosan, $\mathrm{S} \rightarrow$ salicylaldehydechitosan, $\mathrm{G} \rightarrow$ glutaraldehyde-chitosan)

of nitrogen present in the amine groups could form coordination bonds with iron (II) ions. Part of these amine groups was consumed during formation of Schiff bases of chitosan, which resulted in a significant decrease in the adsorption capacity (Inoue et al., 1993). At the same time, the cross-linking in the synthesized derivatives could reduce the accessibility of iron (II) ions to the internal adsorption sites on chitosan chain.

\section{Conclusion}

This study has shown that chitosan, vanillin-chitosan, salicylaldehyde-chitosan and glutaradehyde-chitosan are capable of removing iron (II) ions from aqueous solution. The iron (II) removal efficiency depended on contact time and iron (II) concentration of the solution. The amount of adsorption of iron (II) increased with the increase of initial dye concentration. The equilibrium adsorption data were fitted to Freundlich and Langmuir adsorption isotherm models and the model parameters were evaluated. Both the models represent the experimental data satisfactorily. The present findings suggest that chitosan and its chitosan derivatives can be used as effective chelating biomaterials for removal of metal ions from aqueous solution. These derivatives may be also utilized for developing efficient drug delivery vehicles. Moreover, these bases can be used as biodegradable biosorbents in pharmaceutical process and API industries.

\section{References}

Bhatnagar, A. and Sillanpää, M. 2009. Applications of chitin- and chitosan-derivatives for the detoxification of water and wastewater - a short review. Adv. Colloid Interface Sci. 152, 2638.

Christian, G. D., 1986. Analytical Chemistry, Fourth Edition, John Wiley \& Sons, New York, p. 598.

Doğan, M., Alkan, M., Demirbas, Ö., Ozdemir Y. and Ozmetin, C. 2006. Adsorption kinetics of maxilon blue GRL onto sepiolite from aqueous solutions. Chem. Eng. J. 124, 89-101.

dos Santos, J.E., Dockal, E.R. and Cavalheiro, É.T. 2005. Synthesis and characterization of Schiff bases from chitosan and salicylaldehyde derivatives. Carbohydr. Polym. 60, 277-282.

Dutkiewicz, J., Szosland, L., Kucharska, M., Judkiewicz, L. and Ciszewski, R. 1990. Structure-bioactivity relationship of chitin derivatives. Part I. The effect of solid chitin derivatives on blood coagulation. J. Bioact. Compat. Polym., 5, 293-304.

Freundlich, H.M.F. 1906. Uber die adsorption in losungen. Z. Phys. Chem. 57, 85-470.

Goosen, M.F.A. 1996. Applications of Chitin and Chitosan. Taylor \& Francis.

Guibal, E., Dambies, L., Milot, C. and Roussy, J. 1999. Influence of polymer structural parameters and experimental conditions on metal anion sorption by chitosan. Polym. Int. 48, 671-680. 
Guo, Z., Xing, R., Liu, S., Zhong, Z., Ji, X., Wanga, L., et al. 2007. Antifungal properties of Schiff bases of chitosan, N-substituted chitosan and quaternized chitosan. Carbohydr. Res. 342, 13291332 .

Gupta, K.C and Jabrail, F.H. 2007. Glutaraldehyde cross-linked chitosan microspheres for controlled release of centchroman. Carbohydr. Res. 342, 2244-2252.

Hall, L.D. and Yalpani, M. 1980. Enhancement of the metalchelating properties of chitin and chitosan. Carbohydr. Res. 83, C5-C7.

Hirano, S., Matsuda, N., Miura, O. and Iwaki, H. 1979. Some Narylidenechitosan gels. Carbohydr. Res. 71, 339-343.

Ho, Y.S., Chiang, T.H. and Hsueh, Y.M. 2005. Removal of basic dye from aqueous solutions using tree fern as a biosorbent. Process Biochem. 40, 119-124.

Inoue, K., Baba, Y. and Yoshizuka, K. 1993. Adsorption of metal ions on chitosan and crosslinked copper (II)-complexed chitosan. Bull. Chem. Soc. Jpn. 66, 2915-2921.

Jameela, S.R. and Jayakrishnan, A. 1995. Glutaraldehyde crosslinked chitosan microspheres as a long acting biodegradable drug delivery vehicle: studies on the in vitro release of mitoxantrone and in vivo degradation of microspheres in rat muscle. Biomaterials 16, 769-775.

Kim, S.K. 2013. Chitin and Chitosan Derivatives: Advances in Drug Discovery and Developments. 1st edition, CRC Press.

Kumar, M.N.V.R., Muzzarelli, R.A.A., Muzzarelli, C., Sashiwa, H., and Domb, A. J. 2004. Chitosan chemistry and pharmaceutical perspectives. Chemical Reviews 104, 6017-6084.

Kumirska, J., Czerwicka, M., Kaczyński, Z., Bychowska, A., Brzozowski, K., Thöming, J. and Stepnowski, P. 2010. Application of Spectroscopic Methods for Structural Analysis of Chitin and Chitosan. Mar. Drugs, 8, 1567-1636.

Langmuir, I. 1916. The constitution and fundamental properties of solids and liquids. Part I. J. Am. Chem. Soc. 38, 2221-2295.

Murata, J., Saiki, I., Nishimura, S., Nishi, N., Tokura, S. and Azuma, I. 1989. Inhibitory effect of chitin heparinoids on the lung metastasis of B16-BL6 melanoma. Jpn. J. Cancer Res., 80, 866872

Muslim, T., Morimoto, M., Saimoto, H. and Shigemasa, Y. 2001a. Synthesis of some chitosan hybrids and their metal adsorption capacities. Chitin Chitosan Res., 7, 9-18.

Muslim, T, Morimoto, M., Saimoto, H., Okamoto, Y., Minami, S. and Shigemasa, Y. 2001b. Synthesis and bioactivities of poly (ethylene glycol)-chitosan hybrids. Carbohydr. Polym. 46, 323330.

Muzzarelli, R.A.A. 1973. Natural Chelating Polymers. Pergamon Press, New York, p. 83.

Muzzarelli, R.A.A. and Ilari, P. 1994. Chitosans carrying the methoxyphenyl functions typical of lignin. Carbohydr. Polym., 23, $155-160$.
Nishimura, S., Nishi, N., Tokura, S., Nishimura, K. and Azuma, I. 1986. Bioactive chitin derivatives. Activation of mouse peritoneal macrophages by O-(carboxymethyl)chitins Carbohydr. Res., 146, 251-258.

No, H.K. and Meyers, S.P. 2000. Application of chitosan for treatment of wastewaters. Rev. Environ. Contam. Toxicol. 163, 1-27.

Peng, H., Xiong, H., Li, J., Xie, M., Liu, Y., Bai, C. and Chen L. 2010. Vanillin cross-linked chitosan microspheres for controlled release of resveratrol. Food Chemistry 121, 23-28.

Poon, L., Wilson, L.D. and Headley, J.V. 2014. Chitosanglutaraldehyde copolymers and their sorption properties. Carbohydr. Polym. 109, 92-101.

Rinaudo, M. 2006. Chitin and chitosan: Properties and applications. Prog. Polym. Sci., 31, 603-632.

Rødde, R. H., Einbu A. and Vårum, K.M. 2008. A Seasonal study of the chemical composition and chitin quality of shrimp shells obtained from northern shrimp (Pandalus borealis). Carbohydr. Polym. 71, 388-393.

Sarmento, B. and Neves, J.D. 2012. Chitosan-Based Systems for Biopharmaceuticals: Delivery, Targeting and Polymer Therapeutics. John Wiley \& Sons.

Sashiwa, H. and Aiba S. 2004. Chemically modified chitin and chitosan as biomaterials. Prog. Polym. Sci. 29, 887-908.

Shigemasa, Y. and Minami, S. 1995. Applications of chitin and chitosan for biomaterials. Biotechnol. Genetic Eng. Rev. 13, $383-420$.

Shigemasa, Y., Matsuura, H., Sashiwa, H. and Saimoto, H. 1996 Evaluation of different absorbance ratios from infrared spectroscopy for analyzing the degree of deacetylation in chitin. Int. J. Biol .Macromol. 18, 237-242.

Tanigawa, T., Tanaka, Y., Sashiwa, H., Suzuki, H., Saimoto, H. and Shigemasa, Y. (1992). Various biological effects of chitin derivatives. In: Advances in Chitin and Chitosan (Brine, C. J., Sandford, P. A. and Zikakis, J. P., Eds.), Elsevier Applied Science, London and New York, pp. 206-215.

Terada, N., Morimoto, M., Saimoto, H., Okamoto, Y., Minami, S. and Shigemasa, Y. 1999. Synthesis of water-soluble oxidized chitosan derivatives and their biological activity. Chem. Lett., $1285-1286$

Vårum, K.M., Antohonsen, M.W., Grasdalen, H. and Smidsrød, O. 1991. Determination of the degree of $\mathrm{N}$-acetylation and the distribution of $\mathrm{N}$-acetyl groups in partially $\mathrm{N}$-deacetylated chitins (chitosans) by high-field n.m.r. spectroscopy. Carbohydr. Res. 211, 17-23.

Yalpani, M., Johnson, F. and Robinson, L. E. 1992. Antimicrobial activity of some chitosan derivatives. In: Advances in Chitin and Chitosan (Brine, C. J., Sandford, P. A. and Zikakis, J. P., Eds.), Elsevier Applied Science, London and New York, pp. 543-548. 